\title{
Komunikasi Pemasaran Digital sebagai Tantangan Teknologi
}

\author{
Digital Marketing Communication as a technology challenge
}

\author{
Yulia Sari ${ }^{1}$, Nadia Wasta Utami ${ }^{2}$ \\ 1,2 Program Studi Ilmu Komunikasi, Universitas Islam Indonesia, Sleman \\ Yogyakarta, Indonesia
}

\section{Author's email: \\ ${ }^{1}$ Email: yoeliasr@gmail.com \\ 2 nadia.wasta@uii.ac.id}

\begin{abstract}
The rise of internet users directly influences the usage of e-commerce platform in Indonesia. This growth also influences the competition between brands whom utilize e-commerce platform, hence companies need to address digital marketing communication as primary tools to compete in consumer market. As one of the most well-known shoes brand in Indonesia, Amazara fully realizes the potential of digital marketing sector and trying to implement digital marketing communication as one of its primary marketing strategy. This research examines the chosen communication strategy of Amazara in digital and internet platform. Primary data was taken from in-depth interview with owner and employees. Collected data was classified into categories and processed through data implementation to understand the depth knowledge about this specific case. Interpretation results were compared with theoretical context from literature studies, and formulated to reach primary conclusion. The results of the study indicate that the company has carried out planning and evaluation to develop digital marketing. The company has also developed an AIDA-based digital marketing strategy
\end{abstract}

Keywords: digital, marketing communication, Amazara

Meningkatnya pengguna internet memiliki dampak langsung terhadap kenaikan pemanfaatan kanal e-commerce di Indonesia. Kenaikan ini turut berdampak pula pada persaingan merek yang memanfaatkan e-commerce, sehingga perlu bagi perusahaan untuk mulai mempertimbangkan komunikasi pemasaran digital sebagai senjata utama memenangkan persaingan. Amazara sebagai salah satu merek sepatu ternama di Indonesia menyadari sepenuhnya hal tersebut, dan mulai mengimplementasikan komunikasi pemasaran digital dalam aktifitas pemasarannya. Penelitian ini bertujuan untuk mengetahui dan memaparkan tentang komunikasi pemasaran dengan media digital dan internet yang dipilih Amazara. Data primer diambil dari in-depth interview dengan segenap karyawan dan pemilik Amazara. Data kemudian diklasifikasikan kedalam kategori-kategori tertentu dan diproses melalui interpretasi data untuk mendapatkan pemahaman mendalam terkait kasus. Hasil interpretasi kemudian dibandingkan dengan konteks teoritis yang didapatkan dari studi literatur untuk kemudian diproses dalam proses perumusan kesimpulan. Hasil penelitian menunjukkan bahwa perusahaan telah melakukan perencanaan dan evaluasi untuk mengembangkan mengembangkan pemasaran digital. Perusahaan juga telah mengembangkan strategi pemasaran digital berbasis AIDA

Kata kunci: digital, komunikasi pemasaran, amazara 


\section{PENDAHULUAN}

Era globalisasi menyebabkan pengguna internet, khususnya di Indonesia, semakin meningkat. Pada penelitian Harahap (2018) menyebutkan bahwa masyarakat Indonesia menggunakan e-commerce karena tertarik akan kemudahan yang diberikan dari fasilitas e-commerce.

Konsumen e-commerce di Indonesia didominasi oleh perempuan. CNN (2018) merilis data yang menyebutkan bahwa 66.28 persen barang yang terjual di e-commerce platform Tokopedia dibeli oleh pengguna perempuan. Dari angka pengguna tersebut, 46.33 persen pembeli perempuan berada dalam kisaran usia 20-29 tahun. Lebih lanjut lagi, Jayani (2019) menyebutkan bahwa komoditas fashion merupakan komoditas dengan nilai transaksi paling tinggi dan diprediksi akan mencapai angka transaksi sebesar US\$ 11.9 miliar pada tahun 2023.

Berdasarkan data-data yang dipaparkan, komoditas fashion yang menyasar pasar perempuan berusia 20-29 tahun memberikan peluang yang menarik bagi pelaku bisnis untuk terlibat di dalamnya. Salah satu penyedia kebutuhan fashion perempuan yang cukup ternama di Indonesia adalah Amazara yang memiliki nama resmi PT. Amazara Cipta Indonesia. Berdiri sejak 2015, Amazara menggeluti bidang fashion perempuan, khususnya alas kaki yang diproduksi sendiri. Kiprahnya selama bertahun-tahun di industri fashion membuat merek Amazara telah cukup dikenal di kalangan masyarakat peminat fashion yang dibuktikan dengan jumlah pengikut Amazara di media sosial Instagram telah mencapai angka 300 ribu pengikut. Angka ini merupakan modal yang kuat untuk bersaing dalam persaingan industri fashion di Indonesia.

Amazara mengandalkan excellent service dengan tagline 'Delivering the best customer's experience'. Amazara konsisten memaksimalkan promosi melalui online media, antara lain melalui laman web www.amazara.co.id, akun media sosial
Instagram dengan nama akun @amazara.id, akun Line@, YouTube, dan beberapa kanal media sosial lainnya. Upaya untuk meningkatkan kinerja dan kemudahan akses konsumen dilakukan Amazara dengan bekerjasama bersama e-commerce platform Tokopedia dan Shopee untuk membuat konsumen lebih mudah mengakses produk Amazara. Peneli-tian ini bertujuan untuk mengetahui dan memaparkan tentang strategi komunikasi pemasaran dengan media digital dan internet yang dipilih

Amazara dalam memasarkan produknya dan mempertahankan pasar penjualan. Amazara selama ini dikenal sebagai perusahaan yang menjual sepatu dan tas wanita dengan customer yang tersebar di berbagai provinsi di Indonesia, dan penelitian ini menarik untuk diteliti karena di dalamnya merupakan penerapan prinsip-prinsip komunikasi pemasaran terpadu yang mengadaptasi trend gaya hidup digital, yang pada dasarnya merupakan sesuatu yang berkaitan dengan ide-ide yang dituangkan dalam dunia digital.

Secara umum, penelitian ini memiliki tujuan untuk mengetahui pemanfaatan media digital-internet dalam strategi komunikasi pemasaran yang dilakukan oleh PT Amazara Cipta Indonesia.

Dengan menjawab pertanyaan tersebut, penelitian ini diharapkan dapat memberikan pemahaman tentang bagaimana strategi komunikasi pemasaran yang digunakan PT Amazara Cipta Indonesia. Selain itu, penelitian ini diharapkan dapat memberikan pengetahuan, gambaran, masukan dan bahan pertimbangan bagi semua pihak tentang ilmu komunikasi khususnya pada bidang strategi komunikasi pemasaran.

\section{LANDASAN TEORI}

Definisi dari Järvinen et al (2013), pemasaran digital sebagai pendekatan pemasaran yang benar-benar baru, tidak hanya menambahkan unsur digital ke dalam 
pemasaran konvensional. Pendekatan baru ini sebagaimana dijelaskan oleh Taiminen \& Karjaluoto (2015) membutuhkan perusahaan untuk memahami karakteristik dan dinamika tersendiri sebagai upaya pemanfaatan efektif dalam hal taktik atau praktik pemasaran. Lebih lanjut, Hidayat \& Tobing (2012) mengemukakan bahwa bahwa pemasaran digital memberikan keuntungan berupa kemampuan perusahaan dalam mencapai lebih banyak konsumen melalui pendekatan global. Pemaparan-pemaparan ini memberikan pemahaman bahwa pemasaran digital merupakan pendekatan pemasaran yang memiliki karakteristik dan dinamika tersendiri, namun memberikan keuntungan yang besar bagi perusahaan.

Pemasaran digital memiliki jalur atau saluran tertentu yang dapat digunakan oleh perusahaan dan dibedakan berdasarkan pola komunikasi dan pengendalian perusahaan terhadap jalur tersebut. Klasifikasi Taiminen \& Karjaluoto (2015) jalur pemasaran digital kedalam Tabel 1. sebagai berikut:

Tabel 1. Klasifikasi Jalur Pemasaran Digital

\begin{tabular}{lll}
\hline & Kendali Penuh Perusahaan & Kendali Sebagian Perusahaan \\
\hline Satu Arah & Laman Web & Search Engine Optimization \\
& Reklame Digital & Search Engine Advertising \\
Dua Arah & Komunitas Merek & Media Sosial \\
\hline
\end{tabular}

Tabel 1. memberikan pandangan bahwa jalur pemasaran digital dapat diklasifikasikan berdasarkan kendali perusahaan dan arah komunikasi yang dilakukan perusahaan. Secara umum, penjelasan mengenai klasifikasi ini dijelaskan oleh Taiminen \& Karjaluoto (2015) sebagai berikut.

1) Satu arah, dimana komunikasi berlangsung satu arah dari perusahaan ke konsumen;

2) Dua arah, dimana komunikasi berlangsung dua arah dari perusahaan ke konsumen dan sebaliknya;

3) Kendali penuh, dimana perusahaan memiliki kendali penuh atas aktifitas pemasaran digital yang dilakukan dan dampaknya bagi perusahaan;

4) Kendali sebagian, dimana perusahaan memiliki kendali sebatas upaya memaksimalkan upaya pemasaran digital, namun dampak dari aktifitas tersebut berada di luar kendali perusahaan.
Pemasaran digital memiliki langkahlangkah yang unik dalam memasarkan produk. Upaya perusahaan untuk melakukan pemasaran digital perlu untuk memperhatikan kerangka strategi pemasaran sebagai landasan untuk merumuskan tindakan. Di dalam penjelasan Johar (2015) menyatakan bahwa salah satu landasan yang dapat digunakan dalam pemasaran digital adalah model AIDA (attention, interest, desire, action) yang akan dijelaskan sebagai berikut.

a) Awareness (Kesadaran)

Dalam ranah digital, pemasar membangun kesadaran konsumen akan produk atau jasa yang akan ditawarkan

b) Interest (Ketertarikan)

Konsumen yang telah memiliki kesadaran akan merek atau produk dan jasa berpotensi tertarik akan merek atau produk dan jasa tersebut. Tahap ini merupakan tahap dimana konsumen secara aktif mencari informasi terkait. 
c) Desire (Keinginan)

Timbul keyakinan pada konsumen sehingga konsumen berkeinginan atau berniat untuk mencoba produk atau jasa yang ditawarkan

d) Action (Tindakan)

Tahap terakhir sebagai penentuan dari pihak konsumen terhadap produk atau jasa. Pada tahap ini, konsumen memutuskan untuk melakukan tindakan terkait produk atau jasa yang ditawarkan

Model AIDA dapat digunakan untuk merumuskan langkah-langkah pemasaran yang dapat dilakukan oleh perusahaan berdasarkan reaksi konsumen terhadap langkah-langkah tersebut. Di dalam penjelasan Kotler \& Keller (2016) menyebutkan bahwa secara umum, terdapat empat metode pemasaran digital yang dapat dilakukan perusahaan.

a) Pemasaran daring, dimana perusahaan menyampaikan informasi yang ingin disampaikan melalui media daring, baik yang berbayar atau tidak berbayar. Pemasaran daring dapat dilakukan melalui laman web, search ads, display ads, dan pesan elektronik;

b) Media sosial, dimana perusahaan dapat menampilkan suara publik melalui kehadiran mereka dalam interaksi antar konsumen. Secara umum, media sosial dapat diklasifikasikan kedalam tiga kategori: komunitas dan forum online, blog, serta social network;

c) Word of Mouth (EWOM), dimana interaksi antar konsumen tercipta baik secara generik atau diinisiasi oleh perusahaan. Metode ini membuat perusahaan perlu untuk mengendalikan interaksi yang dilakukan oleh konsumen;

d) Mobile marketing, dimana pemasaran dilakukan melalui gawai-gawai pintar yang digenggam dan diakses oleh konsumen sehari-hari.

Pelaku pemasaran saat ini memiliki solusi komunikasi pemasaran yang lebih luas dengan berkembangnya pemasaran digital. Perkembangan ini disebabkan oleh perkembangan teknologi, saluran komunikasi pemasaran, dan alat komunikasi pemasaran yang tersedia. Beberapa hambatan dalam menerapkan komunikasi pemasaran digital sebagaimana dijelaskan oleh Bostanshirin (2014) adalah sebagai berikut.

a) Permasalahan integrasi, dimana komunikasi pemasaran digital memanfaatkan saluran-saluran baru yang terpisah, memiliki karakter spesifik dan berdiri sendiri-sendiri satu sama lain. Karakteristik ini menyebabkan pemasar seringkali mendapatkan kesulitan saat berupaya mengintegrasikan masing-masing strategi komunikasi di tiap-tiap saluran.

b) Kekurangan interaksi langsung, dimana komunikasi pemasaran digital mengurangi pengalaman konsumen dalam mendapatkan interaksi langsung bersifat fisik dengan perusahaan. Permasalahan ini disebut dapat menyebabkan berkurangnya persepsi konsumen dan pengalaman interaksi konsumen terhadap produk yang dipasarkan.

c) Keamanan dan privasi, dimana metode komunikasi pemasaran digital membutuhkan data konsumen yang disimpan dalam cloud - metode penyimpanan yang mengandalkan server berbasis daring. Data ini rentan disalahgunakan oleh pihak tertentu, atau bahkan dimanfaatkan perusahaan untuk kepentingankepentingan tertentu pula.

d) Kekurangan kepercayaan, dimana konsumen masih berupaya beradaptasi dengan metode baru yang 
mereka miliki. Hal ini membuat konsumen memiliki beberapa keraguan terkait komunikasi pemasaran digital yang mereka terima.

\section{METODE PENELITIAN}

Jenis dan Pedekatan Penelitian Penelitian ini menggunakan pendekatan kualitatif dengan metode studi kasus. Cooper \& Schindler (2014) menyatakan bahwa penelitian kualitatif dilakukan dalam upaya mendalami dan memahami motivasi tersirat dari individu melalui interpretasi dan pemahaman akan informasi yang disampaikan.

\section{TEMUAN DAN PEMBAHASAN}

Komunikasi pemasaran digital merupakan sebuah konsep pemasaran yang benar-benar baru, dan tidak hanya menambahkan elemen digital ke dalam komunikasi pemasaran konvensional (Järvinen et al., 2013). Keberhasilan perusahaan dalam melakukan komunikasi pemasaran digital memberikan keuntungan berupa kemampuan perusahaan dalam menjaring lebih banyak konsumen melalui pendekatan global (Hidayat \& Tobing, 2012).

Johar (2015) menyatakan bahwa salah satu landasan dalam melakukan komunikasi pemasaran digital adalah model AIDA. Model ini digunakan dengan pendekatan berbasis reaksi konsumen akan langkah-langkah pemasaran yang disusun perusahaan dan perusahaan akan merumuskan langkah komunikasi pemasaran digital berbasis reaksi tersebut. Langkah pembaharuan terus-menerus ini penting untuk dilakukan mengingat perubahan pola konsumen yang terus menerus terjadi dan seringkali sulit diprediksi oleh perusahaan (Johar, 2015).

Memahami value yang ingin disampaikan pada konsumen merupakan fondasi utama dalam merumuskan rancangan komunikasi pemasaran digital yang dilakukan Amazara. Upaya Amazara dalam merumuskan value dilakukan dengan mendalami kebutuhan dan keinginan konsumen melalui survei langsung ke konsumen, sebagaimana dinyatakan oleh Head of Social Media Amazara berikut.

"Value ini haruslah yang bisa
menjawab keresahan dari customer
online. Jadi, kayak apa sih keresahan
yang dirasakan sama customer online
tuh? Nah dari situ, kita tau value apa
yang bisa kita tawarkan." (Mega
Aguend, Head of Marketing Amazara,
wawancara, 3 Juli 2020)

Amazara meyakini bahwa menentukan value yang sesuai dengan kebutuhan dan keinginan konsumen akan membuat konsumen mulai melirik keberadaan produk Amazara. Perilaku ini sejalan dengan langkah pertama dalam model AIDA, yaitu attention - dimana pemasar membangun kesadaran konsumen akan produk atau jasa yang akan ditawarkan (Johar, 2015)

Langkah selanjutnya dalam model AIDA adalah interest, yang dijelaskan oleh Johar (2015) sebagai tahap dimana konsumen berpotensiuntuk tertarik menjadikan Amazara sebagai pilihan dalam berbelanja. Pemaparan yang disampaikan oleh Head of Marketing Amazara menyebutkan bahwa Amazara menciptakan ketertarikan konsumen melalui implementasi bauran pemasaran. Kotler \& Keller (2016) menjelaskan bahwa bauran pemasaran adalah seperangkat alat pemasaran taktis yang diintegrasikan oleh perusahaan dalam upaya memproduksi reaksi yang diharapkan dari konsumen. Lebih lanjut, dinyatakan bahwa bauran pemasaran terdiri dari empat elemen utama: produk, harga, lokasi, dan promosi.

Amazara percaya bahwa kualitas produk yang baik merupakan faktor utama dalam keberhasilan pemasaran yang dilakukan. Langkah lebih lanjut dalam menciptakan ketertarikan konsumen adalah menentukan harga yang tepat bagi produk atau jasa yang diberikan perusahaan. Penetapan harga yang 
dilakukan Amazara berbasis pada value Amazara, yaitu "Affordably Stylish". Value ini membuat penetapan harga Amazara dilakukan untuk memberikan pilihan sepatu yang terjangkau oleh konsumen mereka. Prinsip ini membuat Amazara harus memahami karakteristik kemampuan finansial konsumen mereka sebelum melakukan penetapan harga, sebagaimana disampaikan oleh Head of Marketing Amazara bahwa target market yang dituju usianya sekitar 17-25 tahun, jadi price point-nya Amazara dulu adalah berkisar antara Rp150.000-Rp250.000.

Sekarang, kita mau memperluas target market kita ke usia 30 tahun-an, jadi price point kita tingkatkan, yaitu antara Rp200.000-Rp349.000. Jadi, price bener bener harus sesuai dengan target market yang kita tuju agar customer tertarik." (Mega Aguend, Head of Marketing Amazara, wawancara, 3 Juli 2020).

Place dijelaskan oleh Kotler \& Keller (2016) sebagai langkah memilih dan mengelola saluran perdagangan yang dipakai untuk menyalurkan produk atau jasa dan juga untuk melayani pasar sasaran. Amazara berupaya untuk mempermudah distribusi dan akses konsumen ke produk Amazara melalui aktivasi toko online dan offline. Tujuan aktivasi ini sebagaimana disampaikan oleh Head of Marketing Amazara adalah memberikan kemudahan kepada customer untuk easy order di channel penjualan manapun. Konsumen dapat melakukan order lewat WhatsApp, Instagram, dan melalui marketplace Tokopedia atau Shopee." (Mega Aguend, Head of Marketing Amazara, wawancara, 3 Juli 2020)

Elemen promotion juga memegang peranan penting dalam menciptakan ketertarikan konsumen. Kotler \& Keller (2016) menjelaskan promotion sebagai sesuatu yang digunakan untuk memberitahukan dan membujukpasar tentang produk atau jasa yang baru pada perusahaan. Dalam konteks menciptakan ketertarikan, Amazara menerapkan tindakan promosi berupa diskon dan penawaran khusus untuk konsumen.

Setelah memancing ketertarikan konsumen, langkah selanjutnya adalah mengkonversi ketertarikan tersebut menjadi keinginan kuat untuk membeli produk. Langkah ini dalam model AIDA adalah desire, dimana Johar (2015) mendefinisikan desire sebagai timbulnya keyakinan pada konsumen sehingga konsumen berkeinginan atau berniat untuk mencoba produk atau jasa yang ditawarkan. Amazara menciptakan desire melalui penanaman sense of urgency bagi konsumen untuk melakukan pembelian secepatnya.

Langkah terakhir dalam model AIDA adalah action atau tindakan konsumen. Pada tahap ini, konsumen memutuskan untuk melakukan tindakan terkait produk atau jasa yang ditawarkan (Johar, 2015). Tugas Amazara dalam proses ini adalah mendukung dan membantu konsumen untuk mempermudah tindakan yang dilakukan konsumen Amazara, sehingga konsumen tidak membatalkan niatnya karena menemui kesulitan-kesulitan dalam proses transaksi. Tindakan Amazara dalam mempermudah konsumen berbasis pada pendekatan easy order dan pemanfaatan friendly customer service.

Layanan ekstra customer service juga menjadi perhatian perusahaan dalam mempermudah konsumen. Penyampaian dari Head of Customer Service Amazara mengungkapkan bahwa tidak hanya melayani konsumen, tetapi juga bertanggung jawab dalam merumuskan atau menyampaikan informasi mengenai preferensi konsumen dalam alur transaksi atau merek Amazara secara keseluruhan.

Penerapan Model AIDA dalam merumuskan fondasi komunikasi pemasaran digital merupakan hal esensial untuk memberikan arah yang padu dalam menciptakan komunikasi pemasaran digital yang efisien. Komunikasi pemasaran digital bukanlah sekadar pelengkap pemasaran 
konvensional, tetapi merupakan sebuah metode baru yang digunakan untuk menunjang strategin pemasaran perusahaan. Beberapa hal yang diterapkan untuk komunikasi pemasaran digital adalah sebagai berikut.

\section{Laman Web Resmi Amazara}



Gambar 1. Tampilan Laman Website Amazara

Tujuan utama Amazara dalam membuat laman web adalah memudahkan konsumen dalam melakukan transaksi mandiri dan memudahkan perusahaan dalam melakukan pendataan konsumen. Appel et al (2020) menyebutkan bahwa fungsi utama laman web adalah mengaktivasi layanan utama dari perusahaan untuk bisa digunakan oleh konsumen dalam segmentasi global.

Hasil aktivasi laman web ini terhitung cukup baik bagi Amazara. Laman web Amazara merupakan salah satu penyumbang transaksi terbesar untuk Amazara, hanya dikalahkan oleh kombinasi saluran marketplace. Laman web Amazara memiliki rasio click per transaction rasio yang menjelaskan berapa persen konsumen yang melakukan transaksi dibandingkan dengan total akses keseluruhan laman web Amazara, sejumlah 3-5 persen dengan jumlah pengunjung laman web berjumlah ribuan hingga belasan ribu setiap harinya. Angka konversi ini dapat dikatakan cukup tinggi, mengingat belum banyak masyarakat yang terbiasa melakukan pembelian melalui laman web.

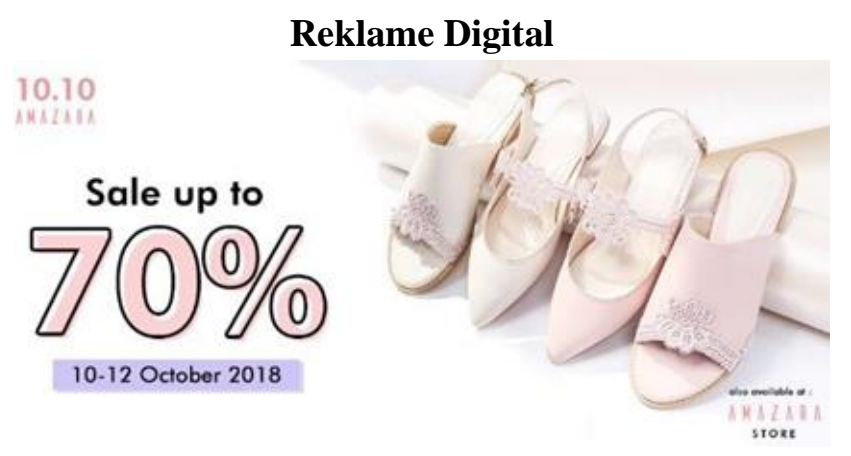

Gambar 2. Contoh Reklame Digital Amazara

Reklame digital sebagaimana dijelaskan Johar (2015) adalah reklame virtual di kanal daring yang berfungsi untuk mempromosikan produk, jasa, aktivasi pemasaran, atau jenis layanan dari sebuah merek. Secara umum, Amazara memfungsikan 
reklame digital sebagai alat pemasaran untuk menjangkau lebih banyak segmentasi pasar konsumen yang mengakses saluran daring lain selain yang telah dibentuk oleh Amazara.

Aktivasi reklame digital di Amazara dirumuskan melalui perbandingan karakteristik konsumen per saluran dan return of investment dari upaya pengiklanan reklame tersebut. Berdasarkan hasil perumusan, ditentukan bahwa reklame digital yang sesuai untuk Amazara adalah reklame di saluran Instagram. Penerapan reklame digital Amazara di Instagram sebagaimana dikutip dari Digital Marketing Strategist Amazara adalah sebagai berikut.

"Instagram $A d s$ ini sendiri biasanya ada beberapa main campaign yang berbeda, misal untuk awareness yang menyasar totally new audience untuk new customer acquisition, kemudian ada untuk sales conversion, dan ada pula untuk customer retaining. Setiap main campaign tersebut memiliki campaign yang berbeda dengan ads yang berbeda dengan masing masing versi untuk A/B testing." (Fajar Bakrie, Digital Marketing Strategist Amazara, wawancara, 25 Juni 2020)

Keberhasilan reklame digital diukur berdasarkan berbagai rasio yang dirumuskan Amazara dalam menentukan standar keberhasilan. Tujuan akhir penetapan rasio ini adalah mengukur apakah pola pemasangan reklame digital sudah cukup efektif untuk dilakukan. Beberapa rasio yang digunakan Amazara adalah sebagai berikut.

1. Impressions

2. Reach

3. Engagements

4. Cost per Click, dan Cost per Purchase

5. Conversion Rate

6. Return on Ad Spend

Secara umum, ada tiga tujuan Amazara dalam memasang reklame digital (atau biasa disebut sebagai ads dalam forum internal).
Tujuan pemasangan ads oleh Amazara, sebagaimana dipaparkan oleh Andrea Naomi, adalah sebagai berikut.

1. Brand awareness. Brand awareness bertujuan untuk membuat masyarakat menjadi tahu keberadaan merek Amazara.

2. Targeting. Targeting bertujuan untuk mengkonversi pemahaman masyarakat terkait Amazara menjadi sebuah tindakan nyata/engage dengan merek Amazara;

3. Conversion. Conversion bertujuan untuk membuat masyarakat yang terpapar oleh ads Amazara berakhir melakukan transaksi dengan Amazara.

Ketiga tujuan di atas ditetapkan dengan mempertimbangkan rasio-rasio yang telah dipaparkan dalam penjelasan sebelumnya. Andrea Naomi mengungkapkan bahwa dalam upaya mengejar brand awareness, maka rasio yang penting untuk dipertimbangkan adalah reach dan impressions.

Andrea Naomi menjelaskan bagaimana Amazara mengukur conversion yang merupakan tujuan ketiga mereka. Secara prinsip, tentu saja, Amazara ingin memiliki nilai konversi transaksi sebesar-besarnya dengan biaya sekecil-kecilnya. Angka ini diukur dengan Return of Ads Spent (ROAS) dan Return of Investment (ROI).

\section{Aktivasi SEO dan SEA}

SEO merupakan sebuah strategi yang bertujuan untuk meningkatkan traffic konsumen menuju laman web perusahaan melalui pemanfaatan search engines (Khraim, 2015). Lebih lanjut lagi, beberapa faktor yang penting untung dipertimbangkan dalam perumusan SEO adalah strategi SEO, daya saing SEO, pengalaman SEO, dan teknik SEO. Kritzinger \& Weideman (2013) merumuskan bahwa perusahaan perlu untuk memanfaatkan SEO untuk meningkatkan traffic laman web perusahaan secara organik. 
Melalui berbagai proses eksperimen, Amazara menemukan bahwa penerapan SEO dan SEA memiliki rasio keberhasilan yang jauh berbeda. Berdasarkan hasil tersebut, Amazara memutuskan untuk memanfaatkan SEO secara maksimal dan sementara berhenti menerapkan SEA dalam praktik pemasaran digitalnya.

Meskipun memiliki efektifitas yang lebih tinggi, penerapan SEO sejatinya tidak memiliki patokan algoritma yang sangat jelas dalam praktiknya. Disampaikan bahwa Amazara berupaya memaksimalkan guidelines yang disampaikan oleh Google dalam modul penerapannya, karena hanya Google yang benar-benar memahami algoritma yang mereka terapkan.

\section{Aktivasi Komunitas}

Kotler \& Keller (2016) menyatakan bahwa komunikasi word of mouth merupakan komunikasi antarkonsumen baik yang terjadi secara organik maupun diinisiasi oleh perusahaan. Brogi (2014) menyatakan bahwa

salah satu cara untuk menginisiasi komunikasi antarkonsumen adalah membentuk brand community - komunitas yang dinaungi perusahaan dan berisikan konsumen dari merek yang dimiliki perusahaan. Brand community Amazara dibentuk dengan nama "Amazara Squad", yang menandakan secara jelas bahwa anggota komunitas tersebut adalah konsumen setia dari Amazara.

\section{Media Sosial Instagram}

Pada penelitian Martinus \& Chaniago (2017) menyebutkan bahwa salah satu media sosial yang memungkinkan perusahaan untuk melakukan storytelling dan meningkatkan citra merek adalah Instagram. Amazara sendiri berfokus dalam meningkatkan eksistensi mereka di Instagram sejak awal berdiri. Aktivitas Amazara di Instagram berlandaskan fokus utama untuk membuat media sosial sebagai "sarana untuk menjalin hubungan dengan konsumen, bukan sebagai media hard selling belaka".

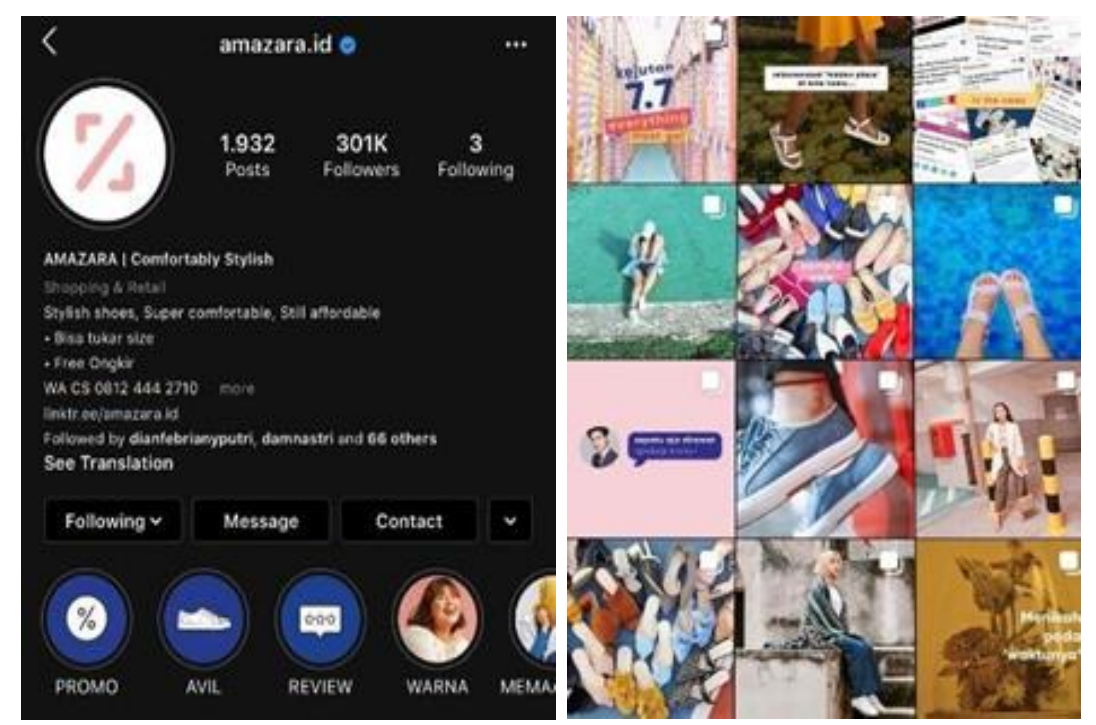

Gambar 3. Tampilan Instagram Amazara

\section{Faktor Pendukung dan Penghambat Komunikasi Pemasaran Digital}

Penerapan komunikasi pemasaran digital yang dilakukan Amazara membutuhkan dukungan-dukungan tertentu dalam upaya mereka mencapai tujuan penerapan strategi komunikasi pemasaran. Faktor pendukung ini diperlukan bagi Amazara untuk memaksimalkan strategi komunikasi pemasaran digital yang mereka lakukan.

Taiminen \& Karjaluoto (2015) memaparkan bahwa perusahaan yang memahami karakteristik pemasaran digital akan meningkatkan efektifitas dari upaya 
komunikasi pemasaran digital itu sendiri. Amazara dalam praktiknya telah memahami apa saja karakteristik spesifik yang penting untuk dipahami dalam menerapkan strategi komunikasi pemasaran digitalnya. Pemahaman tersebut memberikan pandangan bagi Amazara bagai-mana menerapkan langkah-langkah komunikasi pemasaran digital yang efektif. Berdasarkan pemaparan di atas, dapat diketahui bahwa Amazara telah memiliki pengetahuan menge-nai pola-pola komunikasi pemasaran digital yang diharapkan dan efektif di mata konsumen. Pemaparan lanjutan dari Digital Marketing.

Strategist Amazara menambahkan faktor-faktor pendukung penting yang dimiliki Amazara sebagai berikut:

"Komunikasi tim yang baik, ditambah dengan adanya eagerness to learn yang tinggi dari setiap individu di dalam tim akan membantu membangun sinergi yang baik dan pada akhirnya memberikan efek positif pada pelaksanaan campaign, misalnya ada permasalahan yang muncul dapat segera dikomunikasikan dan di-discuss untuk dicarikan solusinya." (Fajar Bakrie, Digital Marketing Strategist Amazara, wawancara, 25 Juni 2020)

Strategi komunikasi pemasaran digital yang dimiliki Amazara juga tidak lepas dari beberapa faktor penghambat yang menjadi batu sandungan bagi Amazara dalam menerapkan strategi komunikasi pemasaran digitalnya. Kotler \& Keller (2016) menyatakan bahwa dalam pemasaran digital, rawan terjadi distorsi pada akurasi interaksi konsumen dan pesan yang ingin disampaikan. Lebih lanjut, Bostanshirin (2014) menyatakan pula bahwa pola komunikasi pemasaran digital masih baru diterima konsumen, sehingga konsumen memiliki keraguan saat menerima informasi. Kedua pemaparan tersebut membuat perusahaan secara umum cukup ragu dalam mengeluarkan anggaran pemasaran digital yang masif, karena efisiensi penerapannya belum dapat diketahui secara pasti. Permasalahan anggaran juga dihadapai Amazara dalam menjalankan komunikasi pemasaran digitalnya.

"Biasanya budget marketing yang too low sih yang jadi penghambat. Kita pengen campaign tersebut bisa gede, nge-reach banyak orang. Cuman budget marketing seringkali cuma sedikit. Pengennya nge-grab KOL yang emang target kita banget nih. Tapi karena budget terbatas, kita Cuma bisa reach KOL yang free." (Mega Aguend, Head of Marketing Amazara, wawancara, 3 Juli 2020)

Permasalahan anggaran membuat Amazara harus menyesuaikan strategi mereka dengan anggaran yang diberikan. Faktor-faktor ketidakpastian dalam penerapan strategi dan kaitannya dengan pemasukan perusahaan membuat perusahaan gamang dalam memberikan anggaran besar dalam kampanye pemasaran digital.

\section{KESIMPULAN}

Penelitian ini bertujuan untuk mengetahui program komunikasi pemasaran digital merek Amazara. Amazara memiliki nilai utama berupa "Affordably Stylish", yang mengemukakan pesan bahwa semua orang berhak tampil stylish, dan melalui landasan inilah Amazara melakukan komunikasi pemasaran digital untuk menjaring dan mempertahankan konsumen agar berbelanja di merek Amazara.

Komunikasi pemasaran digital Amazara dimulai dari perencanaan yang dilaksanakan secara top-down, dan bertujuan untuk menciptakan engagement antara konsumen dan merek. Amazara berupaya menciptakan customer experience yang baik di mata konsumen - dengan fokus kegiatan utama adalah mempermudah konsumen dalam berinteraksi, memanfaatkan fitur, dan bertransaksi dengan Amazara. 
Perencanaan juga melibatkan kalkulasi finansial dengan memberikan alokasi melalui mekanisme penghitungan yang berbeda-beda di setiap program. Lebih lanjut, perencanaan juga mempertimbangkan saluran komunikasi pemasaran digital apa yang akan dipilih.

Evaluasi sendiri dilakukan Amazara dengan melihat penerimaan konsumen atas langkah-langkah komunikasi pemasaran digital. Konsumen secara umum memiliki pandangan positif atas komunikasi pemasaran yang dilakukan. Hal ini dapat dilihat dari lonjakan pengikut dan visitors kanal informasi Amazara di Instagram dan laman web yang konsisten tiap harinya.

Hasil wawancara dengan tiga orang konsumen Amazara menyebutkan bahwa daya tarik komunikasi pemasaran digital Amazara terletak pada jenis konten yang dipublikasikan, layanan customer service yang responsif, identitas merek yang jelas, serta kesesuaian konten dengan preferensi konsumen. Respon konsumen ini juga membuktikan bahwa komunikasi pemasaran digital yang dilakukan Amazara mampu memancing awareness dan ketertarikan konsume, memancing desire konsumen untuk melakukan pembelian, dan memfasilitasi aktifitas pembelian itu sendiri.
Beberapa faktor pendukung yang mengakselerasi komunikasi pemasaran digital Amazara adalah pemahaman tim Amazara terkait karakteristik spesifik yang penting untuk dipahami dalam menerapkan komunikasi pemasaran digital. Lebih lanjut lagi, komunikasi yang baik dan keinginan belajar talenta internal Amazara yang tinggi memungkinkan untuk terus mengevaluasi dan memperbaharui komunikasi pemasaran digital Amazara. Selain itu, terdapat pula faktor penghambat dalam komunikasi pemasaran digital Amazara. Faktor-faktor tersebut antara lain akurasi pesan yang ditangkap konsumen, keraguan konsumen dalam menerima informasi, keterbatasan anggaran, dan ketidapkastian pengukuran. Terdapat pula permasalahan integrasi, dimana Amazara kesulitan mengintegrasikan komunikasi pemasaran di tiap saluran.

Berdasarkan hasil temuan penelitian tersebut, peneliti merekomendasikan pentingnya Amazara membuat strategi komunikasi digital jangka panjang. Ini penting agar dampak komunikasi pemasaran menjadi jauh lebih baik. 


\section{DAFTAR PUSTAKA}

Appel, G., Grewal, L., Hadi, R., \& Stephen, A. T. (2020). The future of social media in marketing. Journal of the Academy of Marketing Science, 48(1), 79-95. https://doi.org/10.1007/s11747019-00695-1

Bostanshirin, S. (2014). Online marketing: Challenges and opportunities. International Conference of Social Sciences and Humanities.

Brogi, S. (2014). Online brand communities: A literature review. Procedia - Social and Behavioral Sciences, 109, 385-389. https://doi.org/10.1016/j.sbspro.2 013.12.477

CNN. (2018). Produk fesyen lokal rajai e-commerce, terpuruk di elektronik. CNN Indonesia.

Cooper, \& Schindler. (2014). Bussiners research method. In McGrawHill. McGrawHill.

Harahap, D. A. (2018). Perilaku belanja online di Indonesia: Studi kasus. JRMSI - Jurnal Riset Manajemen Sains Indonesia, 9(2), 193-213.

https://doi.org/10.21009/JRMSI. 009.2.02

Hidayat, N. K., \& Tobing, R. (2012). Enhancing netizen as a digital marketing activity toward strategic branding: A case study of "XYZ" brand. The Winners, 13(1), 58. https://doi.org/10.21512/tw.v13i1. 668
Järvinen, J., Töllinen, A., Karjaluoto, H., \& Jayawardhena, C. (2013). Digital and social media marketing usage in $\mathrm{B} 2 \mathrm{~b}$ industrial section. The Marketing Management Journal, 22(2), 102-117.

http://www.mmaglobal.org/MMJ -Archive/MMJArchives.php

Jayani, D. H. (2019). Tren pengguna e-commerce terus tumbuh. Databoks.Katadata.Co.Id. https://databoks.katadata.co.id/d atapublish/2019/10/10/trenpengguna-e-commerce-2017-2023

Johar, D. S. (2015). Pengaruh aida (attention, interest, desire, action) terhadap efektifitas iklan online (survei pada pembeli di toko online adorable project). Jurnal Administrasi Bisnis, 26(1). http://administrasibisnis.studentj ournal.ub.ac.id/index.php/jab/art icle/view/1031

Khraim, H. S. (2015). The impact of search engine optimization on online advertisement: The case of companies using e-marketing in Jordan. American Journal of Industrial and Business Management, 4(2), 76-84. http://worldscholars.org/index.p $\mathrm{hp} /$ ajbm/article/view/676

Kotler, P., \& Keller, K. L. (2016). Marketing managemen 15th edition. In Pearson Education Limited. Pearson. https://www.pearson.com/us/hig her-education/product/KotlerMarketing-Management-15thEdition/9780133856460.html 
Kritzinger, W. T., \& Weideman, M.

(2013). Search engine

optimization and pay-per-click

marketing strategies. Journal of

Organizational Computing and

Electronic Commerce, 23(3), 273-

286.

https://doi.org/10.1080/1091939

2.2013.808124

Martinus, H., \& Chaniago, F. (2017).

Analysis of branding strategy

through instagram with

storytelling in creating brand

image on proud project.

Humaniora, 8(3), 201.

https://doi.org/10.21512/humani

ora.v8i3.3678

Taiminen, H. M., \& Karjaluoto, H.

(2015). The usage of digital

marketing channels in SMEs.

Journal of Small Business and

Enterprise Development, 22(4),

633-651.

https://doi.org/10.1108/JSBED-

05-2013-0073 
Yulia Sari \& Nadia Wasta Utami 